\title{
KNOWLEDGE, ATTITUDE AND PRACTICES OF INFANT FEEDING PRACTICES AMONG RURAL WOMEN IN EASTERN INDIA
}

Ratan Das $^{1}$, Amitava Mukherjee ${ }^{2}$

\section{HOW TO CITE THIS ARTICLE:}

Ratan Das, Amitava Mukherjee."Knowledge, Attitude and Practices of Infant Feeding Practices among Rural Women in Eastern India". Journal of Evolution of Medical and Dental Sciences 2014; Vol. 3, Issue 02, January 13; Page: 506-512, DOI:10.14260/jemds/2014/1857

BACKGROUND: Poor infant feeding practices and their consequences are one of the world's major problems and a serious obstacle to social and economic development. Breastfeeding is one of the most important determinants of child survival, birth spacing, and the prevention of childhood infections. The beneficial effects of breastfeeding depend on its initiation, duration, and the age at which the breastfed child is weaned. Breastfeeding practices vary among different regions and communities.AIMS AND OBJECTIVES: To assess the knowledge, attitude and practices of infant feeding and, to assess the prevalence of exclusive breastfeeding practices among women in rural area of West Bengal, India.MATERIALS AND METHODS: This cross-sectional study was conducted on mothers of children less than two year of age attending the outpatient department of Malda Medical College and Hospital, a rural medical college in Eastern India. A total of 200 mothers were interviewed who were randomly selected. A structured, pretested and predesigned questionnaire was used to collect information on the socio-demographic profile and infant feeding practice.RESULTS: Mothers of male children were $65 \%$ and female children were $35 \%$. 44\% were literate upto middle school and $28 \%$ with primary education. $14 \%$ mothers were illiterate. $52 \%$ of mothers had the knowledge about initiation of breast feeding within 1 hour of birth whereas only $28 \%$ practiced it. $80 \%$ mothers had the knowledge of exclusive breast feeding but only $60 \%$ practiced it. $24 \%$ of infants had received prelacteal feeds and only $2 \%$ breast fed upto 24 months.CONCLUSIONS: Despite higher rates of early initiation of breastfeeding and exclusive breastfeeding, awareness of the benefits of exclusive breastfeeding was low. Creating an awareness of the advantages of breastfeeding will strengthen and support this common practice in rural communities and avoid early introduction of complementary foods for socio-cultural reasons.

INTRODUCTION: Good nutrition is vital to ensure that the infant develops both physically and mentally to the fullest potential. Poor feeding practices are a major threat to social and economic development. Scientific research, such as the studies summarized in a 2007 review for the U.S Agency for Healthcare Research and Quality (AHRQ) and a 2007 review for the WHO (World Health Organization), have found numerous benefits of breastfeeding for the infant. According to the American Academy of Pediatrics, research shows that breast feeding provides advantages with regard to general health, growth, and development. Not breastfeeding significantly increases risk for a large number of acute and chronic diseases including lower respiratory infection, ear infections, bacteremia, bacterial meningitis, urinary tract infection, and necrotizing enterocolitis ${ }^{1}$. They state that there are a number of studies that show a possible protective effect of breast milk feeding against sudden infant death syndrome, insulin-dependent diabetes mellitus, Crohn's disease, ulcerative colitis, lymphoma, allergic diseases, digestive diseases, and a possible enhancement of cognitive development ${ }^{2}$. But during the early 1900s breastfeeding started to be viewed negatively 
by Western societies, especially in Canada and the USA. These societies considered it a low class and uncultured practice. This coincided with the appearance of improved infant formulas in the mid 19th century.

"Poor infant feeding practices and their consequences are one of the world's major problems and a serious obstacle to social and economic development. It is not only a problem of the developing world, it occurs in many parts of the developed world as well" 3.

Recent scientific evidence reveals that malnutrition has been responsible, directly or indirectly, for $60 \%$ of all deaths among under five children annually. Over $2 / 3$ of these deaths are often associated with inappropriate feeding practices and occur during the first year of life. Only $35 \%$ of infants world-wide are exclusively breastfed during the first four months of life and complementary feeding begins either too early or too late with foods which are often nutritionally inadequate and unsafe. Poor feeding practices in infancy and early childhood, resulting in malnutrition, contribute to impaired cognitive and social development, poor school performance and reduced productivity in later life. Poor feeding practices are, therefore, a major threat to social and economic development as they are among the most serious obstacles to attaining and maintaining health of this important age ${ }^{4}$.

The Government of India for the first time had included specific goals to improve infant feeding practices for reducing the Infant Mortality Rate (IMR), malnutrition and promoting integrated early child development in the 10 th Five-Year Plan. It also aimed to increase the rate of initiation of breastfeeding within $1 \mathrm{~h}$ to $50 \%$ from the current level of $15.8 \%$, and to increase the exclusive breastfeeding rate to $80 \%$ during the first six months from the current level of around $41 \%{ }^{5}$.

Though there have been global movements towards protecting, promoting and supporting breast milk as a part of optimal feeding practices among newborn babies, there exist many discrepancies between what has been recommended and what is being practiced in reality ${ }^{6}$. Breastfeeding practices in rural communities are influenced by their beliefs, social, cultural, and economic factors ${ }^{7}$. Therefore, the present study was undertaken to identify the prevalence of breastfeeding and various factors influencing infant feeding practices in rural area of West Bengal, India. By assessing the knowledge, attitude and practices of mothers regarding their child's feeding, an overview can be obtained about the areas. This information will be useful to policy makers for the formulation of specific interventional programs in the future.

\section{AIM AND OBJECTIVE:}

1. To assess the knowledge, attitude and practices of infant feeding among the study population

2. To assess the prevalence of exclusive breastfeeding practices among women in rural area of West Bengal.

MATERIALS AND METHODS: This cross-sectional study was conducted on mothers of children less than two year of age attending the outpatient department of Malda Medical College and Hospital, a rural medical college in Eastern India. An orally expressed consent was taken by the participating mothers. A total of 200 mothers were interviewed who were randomly selected from the outpatient department over a period of 4 months. A structured, pretested and predesigned questionnaire was used to collect information on the socio-demographic profile (age, parent's education, occupation 
etc.), details on the initiation and duration of breastfeeding and weaning practices. Illiterate mothers were asked to answer the questions orally and were filled in by volunteers.

RESULTS:Table 1 shows that the number of interviewed mothers of children aged less than 6 months and more than 6 months attending the outpatient department were equal. Mothers of male children were $65 \%$ and female children were $35 \%$.

Table 2 shows that highest percentages of mothers $44 \%$ were literate upto middle school followed by $28 \%$ who were educated with primary education. It also shows that $14 \%$ mothers were illiterate. Only $2 \%$ of the mothers were graduate.

In our study, $52 \%$ of mothers had the knowledge about initiation of breast feeding within 1 hour of birth whereas only $28 \%$ practiced it (Table 3). Table 3 also shows only $64 \%$ of mothers had a good opinion about colostrum.

It is observed from Table 4 that, $80 \%$ mothers had the knowledge of exclusive breast feeding but only $60 \%$ practiced it.

In the current study $24 \%$ of infants had received prelacteal feeds (Table 5). It is also observed from Table 5 that, majority of mothers (78\%) practiced breast feeding upto 12 months of age while only $2 \%$ breast fed upto 24 months. $76 \%$ of mothers initiated complementary feeding by 6 months of age. 88\% continued feeding during illness. Local health worker (42\%) was the most frequent counselor regarding feeding followed by Doctor $(20 \%)$.

DISCUSSION:The effective breastfeeding is crucial for getting all the benefits of breastfeeding ${ }^{1}$ 2. Mothers also get benefited as there is reduced risk of premenstrual breast cancer, ovarian cancer and hip fracture 8. In India, the practice of breastfeeding is almost universal, but initiation of breastfeeding is generally quite late and colostrum is discarded ${ }^{8}$. Apart from ineffective positioning and attachment, the various barriers such as mothers' poor awareness about exclusive breastfeeding, fear of inadequacy of breast milk and poor support at family level are known reasons cited by women for giving up breastfeeding early.

In the present study, highest percentages of mothers (44\%) were literate upto middle school followed by $28 \%$ who were educated with primary education. $14 \%$ mothers were illiterate. Knowledge among the educated mothers was highest. Higher the educational status of the family, of the father, mother or both, the lower the percentage of infants exclusively breastfed for even three months ${ }^{9}$. This indicates that though illiteracy can be a barrier, appropriate health education can have a positive impact on the infant feeding practices.

$52 \%$ of mothers had the knowledge about initiation of breast feeding within 1 hour of birth whereas only $28 \%$ practiced it. The national average of mothers who had initiated breastfeeding within $1 \mathrm{~h}$ after the birth was $23.4 \%{ }^{10}$. A study done by Patricia et al. revealed that $11.6 \%$ infants in urban area and $9.4 \%$ infants in rural area were put to breast within the first hour; $33.3 \%$ infants in urban area and $25.6 \%$ infants in rural area were breastfed within the first day ${ }^{11}$.

$64 \%$ of mothers had good opinion about colostrum. A study by Rajmahal et al., noted that mothers belonging to the higher socioeconomic status had a greater chance of feeding colostrum than the poor income groups ${ }^{12} .80 \%$ mothers had the knowledge of exclusive breast feeding while only $60 \%$ practiced it. A meta-analysis by Arun Gupta and Y. P. Gupta showed that more than half the children (54\%) in the age group of $0-3$ months were exclusively breastfed whereas this percentage 
was much lower (26\%) for children in the age group of 4-6 months ${ }^{13}$.Though there is good knowledge about initiation of breast feeding and exclusive breast feeding in our study, its implication in terms of practicing it are not satisfactory

Prelacteal feed is a popular custom in the society of giving honey, sugar water and water to the newborn ${ }^{14}$. Prelacteal feeds were given to $24 \%$ of infants in our study. A study by Sriram et al showed prelacteal feeds was given to $34.67 \%$ of infant 4 . This custom increases the chances of infection to the infant.

Majority of mothers (78\%) practiced breast feeding upto 12 months of age while only $2 \%$ breast fed upto 24 months.76\% of mothers initiated complementary feeding by 6 months of age. A study from Ahmedabad showed 74.67\% mothers initiated complementary feeding by 6 months but only $29.33 \%$ had the right attributes ${ }^{4}$. $88 \%$ continued feeding during illness which is similar to other study 4 . Local health worker (42\%) was the most frequent counselor regarding feeding followed by Doctor (20\%). This is different from other study where, the most frequent counselor regarding feeding was doctor (58.67\%) ${ }^{4}$. Hence it is essential to educate the mother regarding exclusive breast feeding, timely and appropriate initiation of complementary feeding for adequate growth of the infant.

The small localized population of our study could be a limitation. Hence, the findings in this study cannot be generalized to cover the state or India as a whole.In 1991, Breastfeeding Promotion Network of India (BPNI) was born to protect, promote and support breastfeeding.Recently, the Government of India has undertaken National Rural Health Mission (NRHM), which intends to implement Integrated Management of Neonatal and Childhood Illnesses (IMNCI) through the existing healthcare delivery system.

CONCLUSION:Though many National Health Programs were working for the improvement of mother and child health the prevalence of exclusive breastfeeding has not reached $50 \%$. Creating an awareness of the advantages of breastfeeding will strengthen and support this common practice in rural communities and avoid early introduction of complementary foods for socio-cultural reasons. Health education efforts may be undertaken at village level through monthly Village Health, Nutrition Day (VHND) under National Rural Health Mission.A well-drafted IEC (Information, Education and Communication) activity specifically targeting adolescent girls and antenatal mothers can be implemented. With repeated reinforcement along with research, it might bring a change to the current scenario. The combined support offered by professionals and lay people together improved the breastfeeding - the exclusive breastfeeding and the duration of breastfeeding.

\section{REFERENCE:}

1. Lucas A, Cole TJ. "Breast milk and neonatal necrotising enterocolitis".Lancet.1990; 336(8730): 1519-23.

2. Gartner LM, Morton J, Lawrence RA, et al."Breastfeeding and the use of human milk". Pediatrics. 2005; 115 (2): 496-506.

3. Akri J. Infant feeding: The physiological basis. Bull World Health Organ 1989;67 (1 Suppl):8-9

4. Sriram S, Soni P, Thanvi R, Prajapati N, Mehariya KM. Knowledge, attitude and practices of mothers regarding infant feeding practices. Natl J Med Res. 2013; 3(2): 147-50 
5. National guidelines on infant and young child feeding. Ministry of Human Resource Development. Department of Women and Child development (Food and Nutrition Board). Government of India. http://wcd.nic.in/nationalguidelines.pdf; 2004. p. 2-3.

6. Edmond K, Bahl R. Optimal feeding of low-birth-weight infants. Technical Review. Bull World Health Organ 2006; 30(2): 1-3.

7. Mahmood SE, Srivastava A, Shrotriya VP, Mishra P. Infant feeding practices in the rural population of north India. J Famcommunity med. 2012; 19(2): 130-135.

8. Dongre AR, Deshmukh PR, Rawool AP, Garg BS. Where and how breastfeeding promotion initiatives should focus its attention? A study from rural Wardha. Indian J Community Med. 2010; 35(2): 226-229.

9. Radhakrishnan S, Balamuruga S S. Prevalence of exclusive breastfeeding practices among rural women in Tamil Nadu. Int J Health Allied Sci. 2012; 1:64-7.

10. National Family Health Survey (NFHS-3). Factsheets 2005-2006. Available at URL: http://mohfw.nic.in/nfhsfactsheet.htm accessed on 24/7/2011.

11. Haggerty, Patricia A, Rutstein SO. Breastfeeding and complementary infant feeding, and the postpartum effects of breastfeeding. Demographic and Health Surveys comparative studies17 th edn. Calverton, Md. Macro International, 1999. 145-53.

12. Rajmahal P, Devdas, Mercy Paul VP. Trends in breastfeeding practices. Indian J Nutr Diet 1999; 36:1-10.

13. Gupta A, Gupta YP. Status of infant and young child feeding in 49 districts (98 blocks) of India. A National Report of the Quantitative Study. Breastfeeding Promotion Network of India (BPNI). 2003; 14-8.

14. Kathleen M. McKenna, MPH, SNM, Rani T. Shankar, CNM, MS, MPH. The Practice of Prelacteal Feeding to Newborns Among Hindu and Muslim Families. Journal of Midwifery and Women's Health. 2009; 54(1):78-81.

\begin{tabular}{|c|c|c|}
\hline Age & Number & Percentage (\%) \\
\hline$<6$ month & 100 & $50 \%$ \\
\hline$>6$ month & 100 & $50 \%$ \\
\hline Sex & & \\
\hline Male & 130 & $65 \%$ \\
\hline Female & 70 & $35 \%$ \\
\hline
\end{tabular}

Table 1: Age and sex of infants whose mothers were interviewed

\begin{tabular}{|l|c|c|}
\hline \multicolumn{1}{|c|}{ Education } & Number & Percentage (\%) \\
\hline Illiterate & 28 & $14 \%$ \\
\hline Primary school & 56 & $28 \%$ \\
\hline Middle school & 88 & $44 \%$ \\
\hline High school & 24 & $12 \%$ \\
\hline Graduate & 4 & $2 \%$ \\
\hline \multicolumn{2}{|c|}{ Table 2: Educational status of mother } \\
\hline
\end{tabular}


ORIGINAL ARTICLE

\begin{tabular}{|c|c|c|}
\hline Time of initiating breast feeding & Frequency & Percentage \\
\hline Knowledge & & \\
\hline Within 1 hr. of birth & 104 & $52 \%$ \\
\hline Between 1-4 hr. of birth & 96 & $48 \%$ \\
\hline Between 1-3 days & 00 & 00 \\
\hline Practice & & \\
\hline Within 1 hr. of birth & 56 & $28 \%$ \\
\hline Between 1-4 hr. of birth & 144 & $72 \%$ \\
\hline Between 1-3 days & 00 & 00 \\
\hline Opinion about colostrum & & \\
\hline Good & 128 & $64 \%$ \\
\hline Bad & 72 & $36 \%$ \\
\hline Table 3: Infant feeding attributes \\
\hline
\end{tabular}

\begin{tabular}{|l|c|c|}
\hline \multicolumn{1}{|c|}{ Knowledge } & Frequency & Percentage \\
\hline Exclusive breast feeding & 160 & $80 \%$ \\
\hline Mixed feeding & 40 & $20 \%$ \\
\hline Practice & & \\
\hline Exclusive breast feeding & 120 & $60 \%$ \\
\hline Mixed feeding & 80 & $40 \%$ \\
\hline
\end{tabular}

Table 4: Exclusive breast feeding for 6 months

\begin{tabular}{|l|c|c|}
\hline \multicolumn{1}{|c|}{ Prelacteal feeds } & Frequency & Percentage \\
\hline Given & 48 & $24 \%$ \\
\hline Not given & 152 & $76 \%$ \\
\hline Duration of breast feeding & & \\
\hline 6 months & 20 & $10 \%$ \\
\hline 12 months & 156 & $78 \%$ \\
\hline 18 months & 40 & $10 \%$ \\
\hline 24 months & & $2 \%$ \\
\hline Initiation of complementary feeding & 152 & $76 \%$ \\
\hline 6 months & 8 & $20 \%$ \\
\hline 12 months & & $4 \%$ \\
\hline 18 months & 176 & $88 \%$ \\
\hline Feeding during illness & 24 & $12 \%$ \\
\hline Continued & & \\
\hline Discontinued & 84 & $42 \%$ \\
\hline Counselor & 16 & $20 \%$ \\
\hline Local health worker & 60 & $8 \%$ \\
\hline Doctor & \multicolumn{2}{|c|}{} \\
\hline Relatives & & \\
\hline Not counseled & & \\
\hline &
\end{tabular}




\section{ORIGINAL ARTICLE}

\section{AUTHORS:}

1. Ratan Das

2. Amitava Mukherjee

\section{PARTICULARS OF CONTRIBUTORS:}

1. RMO cum Clinical Tutor, Department of Obstetrics \& Gynaecology, Malda Medical College \& Hospital.

2. Professor, Department of Obstetrics \& Gynaecology, Malda Medical College \& Hospital.

\section{NAME ADDRESS EMAIL ID OF THE} CORRESPONDING AUTHOR:

Dr.Ratan Das,

RMO cum Clinical Tutor,

Department of Obstetrics \& Gynaecology, Malda Medical College \& Hospital.

Email-ranta1982@gmail.com

Date of Submission: 24/12/2013.

Date of Peer Review: 25/12/2013.

Date of Acceptance: 31/12/2013.

Date of Publishing: 11/01/2014 